
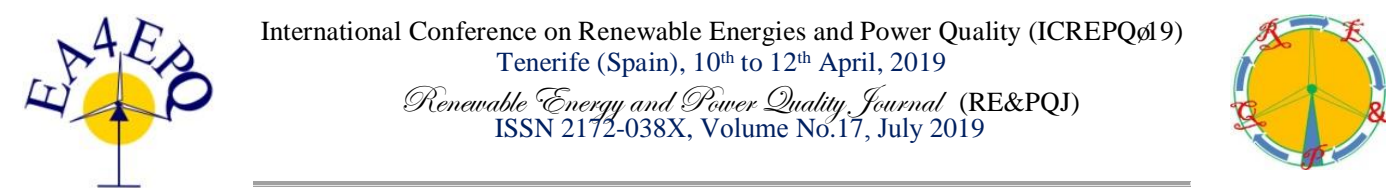

\title{
Preliminary study of a concept of wind-tidal turbine coupling using functional similarities of real time emulation
}

\author{
Cristian Nichita ${ }^{1}$, Mohmed Ashglaf ${ }^{1}$, Yacine Amara ${ }^{1}$, Chul H. Jo ${ }^{2}$ \\ ${ }^{1}$ University of Le Havre - Normandy \\ Research Group in Electrical Engineering and Automatics GREAH \\ 25 Philippe Lebon, BP 1123, Le Havre Cedex, 76063, France \\ Email: cristian.nichita@ univ-lehavre.fr, mohamedshoglaf@yahoo.com \\ ${ }^{2}$ Inha University, Ocean Engineering Laboratory \\ 253 Yonghyun-dong, Inchoen, Korea
}

\begin{abstract}
Horizontal tidal turbine presents important similarities to the wind turbine power systems. Therefore, it would be useful to exploit this similarity to study this important source of energy. In this paper, a new concept of a hybrid offshore windtidal power generation systems coupled electromechanically is studied. Furthermore, a 'time virtual' approach is also presented in order to investigate and compare the energy potentials for given tidal and wind sites. Both the new concept of coupling and virtual time method are simulated in Matlab/Simulink and applyied on Real Time Emulator. Obtained results are presented and disscussed.
\end{abstract}

\section{Key words}

Wind turbine, tidal turbine, hybrid system, real time emulator.

\section{Introduction}

The competitive cost and its purity of toxic emission are the main motivations to develop and research to exploit tidal currents and wind energy. Hybridization of these resources it became an important issue, for reliable electrical networks. Thus, developed methodologies are highly needed to optimize the functionality of decentralized networks. The concept of the tidal turbine is quite similar to a wind turbine. In GREAH Laboratory, multi-function emulator is developed to study the hybridization of windtidal power conversion chain systems [1]. However, the coupling of wind - tidal turbines leads to a complex system which has an unpredictable reflection that may effect on the stability and the performance of the energy system in general.

This work addresses approaches of specific energy management methodologies that firstly established and simulated in Matlab/Simulink environment, for wind and tidal turbines separately, consequently a new concept of

The project is co-financed by European Union with European Regional Development Funds (ERDF) and by the Regional Council of Normandy. hybrid wind - tidal turbine system is develop and simulated [2] [3].

This work focus also, on the technology of power conversion related to the already existed offshore installations, these developments are related to the integration of wind-tidal turbines into the decentralized electrical generation networks (mini and island-networks) designed for the Green Island electrical supply concept.

\section{Similarities Wind-Tidal Turbine}

The functional concepts of horizontal tidal turbine are close to those of a wind turbine. So, fast development could be expected for tidal power generation system, depending on the already developed technologies of wind power systems [4] [5].

Both wind and tidal horizontal turbines operate based on the same principle of energy conversion. In other words, convert the kinetic energy of a fluid into mechanical energy then transforms this later into electrical energy. Despite some differences in the properties of both resources (water and air), but the tidal energy conversion system is very similar to the wind energy conversion system i.e. (have the same structure). Due to the intermittency of the natural resources, these resources can be modeled as nonlinear input with different statistical properties [6].

As the power coefficient $\mathrm{Cp}$ represents the efficiency of the turbine, to convert fluid energy into mechanical energy. In this work, the estimation of this coefficient is based on the theory of Rankine $\ddot{i}$ Froude. Considering incompressible fluids, thus simplify modeling resources to be implemented as input in real time emulator and in control system [7]. Based on these approaches [8], we have developed simulation software that makes it possible to obtain mechanical power as function of rotation speed and some 
other static characteristics of a hybrid system consisting of a wind turbine of $3 \mathrm{~kW}$ at average wind speed $\mathrm{v}=13 \mathrm{~m} / \mathrm{s}$, and a tidal turbine of $3.5 \mathrm{~kW}$, at average tidal current speed of $4 \mathrm{~m} / \mathrm{s}$.

It is supposed that static characteristics of the turbine to be simulated are unknown, turbine static characteristics are obtained using the simulation approach that developed at GREAH lab and are tested at the Inha University (South Korea). These results are validated with real ocean turbine installed in Circulating Water Channel of Inha University Ocean Engineering Laboratory [9]

The qualitative analyses takes into account the wind speed vector in respect to the turbine blades in horizontal axe, for a section of blade at a distance $r$ from the axes of rotated propeller. Figure 1 represents lift and drag forces on a specific section of rotating blade.

The used adopted approach is based on specific methods and modelling algorithms of wind turbine, through which the pitch angle can be changed, starting from its constructive characteristics. These algorithms allow generating the main characteristics of the turbine:

$$
\begin{aligned}
& \text { - Power coefficient } C_{p}=C_{p}(\lambda, \beta) \text { (1) } \\
& \text { - Torque coefficient } C_{\Gamma}=C_{\Gamma}(\Omega, v, \beta)(2)
\end{aligned}
$$

The torque coefficient $\mathrm{C}_{\tilde{u}}$ is calculated as a function of wind or tidal currents speed $\mathrm{v}$, as well as the rotation speed of the turbine rotor $Y$, and angle of incidence $\delta$ [10] [11].By integrating the length of the turbine blade lift and drag forces are obtained:

$$
\mathrm{D}=\frac{1}{2} \mathrm{C}_{\mathrm{x}} \rho \mathrm{v}^{2} \mathrm{~A} ; \mathrm{L}=\frac{1}{2} \mathrm{C}_{\mathrm{z}} \rho \mathrm{v}^{2} \mathrm{~A}
$$

Where;

$\mathrm{C}_{\mathrm{x}}$ and $\mathrm{C}_{\mathrm{z}}$ are, respectively, the dimensionless coefficients, of drag and lift forces; A: is the surface of the blade (the chord multiplied by the blade length); $f$ : Air density; L: lift force and D drag force.

Both suggested turbines have three blades and the pitch angle is considered constant.

Figures 2 and 3 present power characteristics of simulated wind turbine and tidal turbine used in the study.

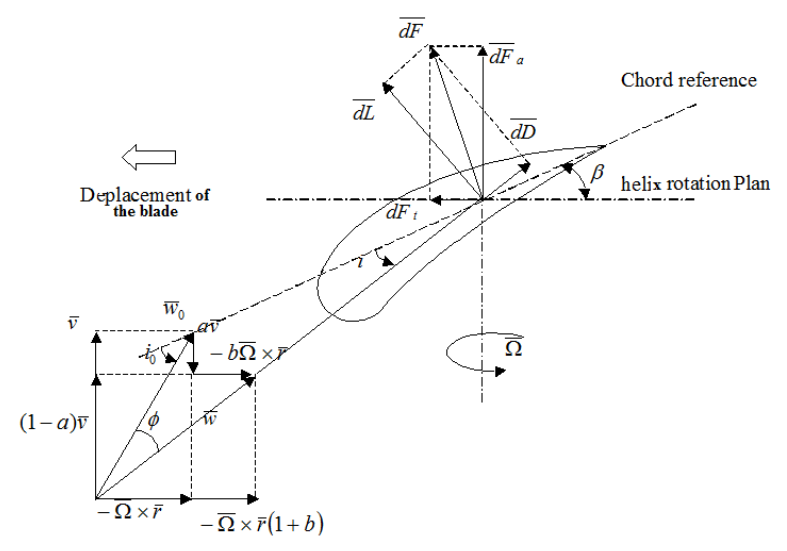

Fig. 1. Representation of speed wind and forces for a section at a distance $\mathrm{R}$ from the axis of the propeller

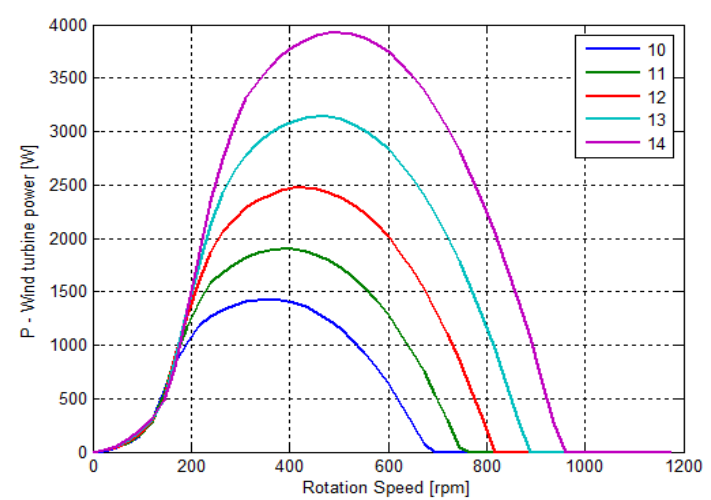

Fig. 2. Characteristics Power - speed of the wind turbine

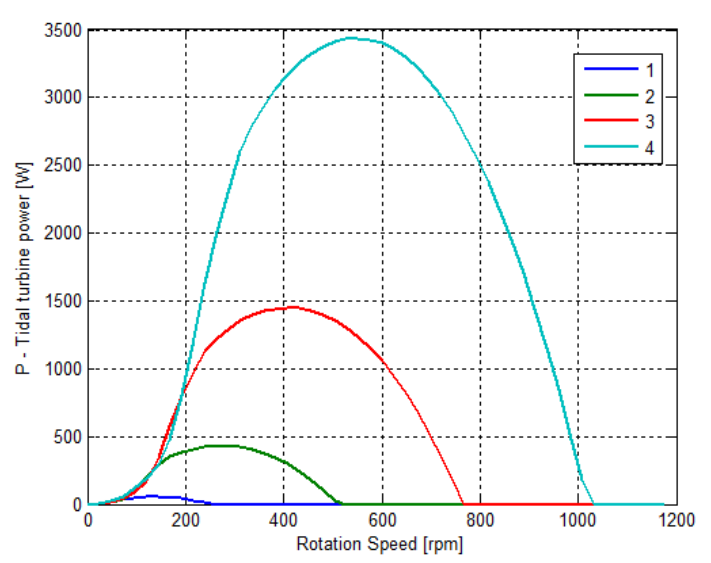

Fig. 3. Characteristic Power ï speed of tidal turbine

\section{Principles of Real-Time Emulation of Actuators}

Emulator components are chosen with very small time constant comparing with the simulated actuators. Speed and torque variation on the actuatorôs shaft vary slower than the corresponding variables of the servo-motor which follows with the smallest possible errors the references (set point) given by the software subsystem. Therefore, errors in the servo loops must be negligible.

Most servo-motors have small time constant and that is why many actuator types can be simulated and extended. This remark is illustrated in figure 5.

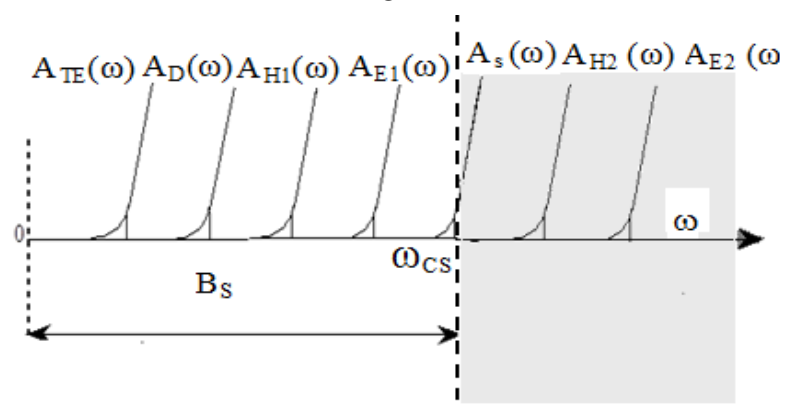

Fig. 4. Bandwidth of the emulator

i)

with the bandwidth Bs corresponding to the several simulated actuators under investigation and emulation control. The emulator bandwidth is defined as the frequency range $(0, \gamma \mathrm{cs})$, in which the attenuation does not exceed a given limit, for example $3 \mathrm{~dB}$ (where $\mathrm{\gamma}$ cs; the cutoff frequency of the subsystem). Consequently, it can be 
consider that the hardware system to be investigated is a wind turbine $A_{T E}(\gamma)$, a diesel motor $A_{D}(\gamma)$, some hydraulic motors $\mathrm{A}_{\mathrm{H} 1}(\mathrm{\gamma}) ; \mathrm{A}_{\mathrm{H} 2}(\boldsymbol{\gamma})$ or some electrical motors $A_{E 1}(\gamma) ; A_{E 2}(\gamma)$.

Figure 5 illustrates the complete structure of the hardware hybrid wind-tidal emulator system [14]:
Electro-mechanical system consisting of:

1) A vector controlled asynchronous motor is used to drive a Doubly-Fed Induction Generator [13]. It is powered by a built-in frequency converter, to allow the adjustment of its speed. This electrical drive emulates

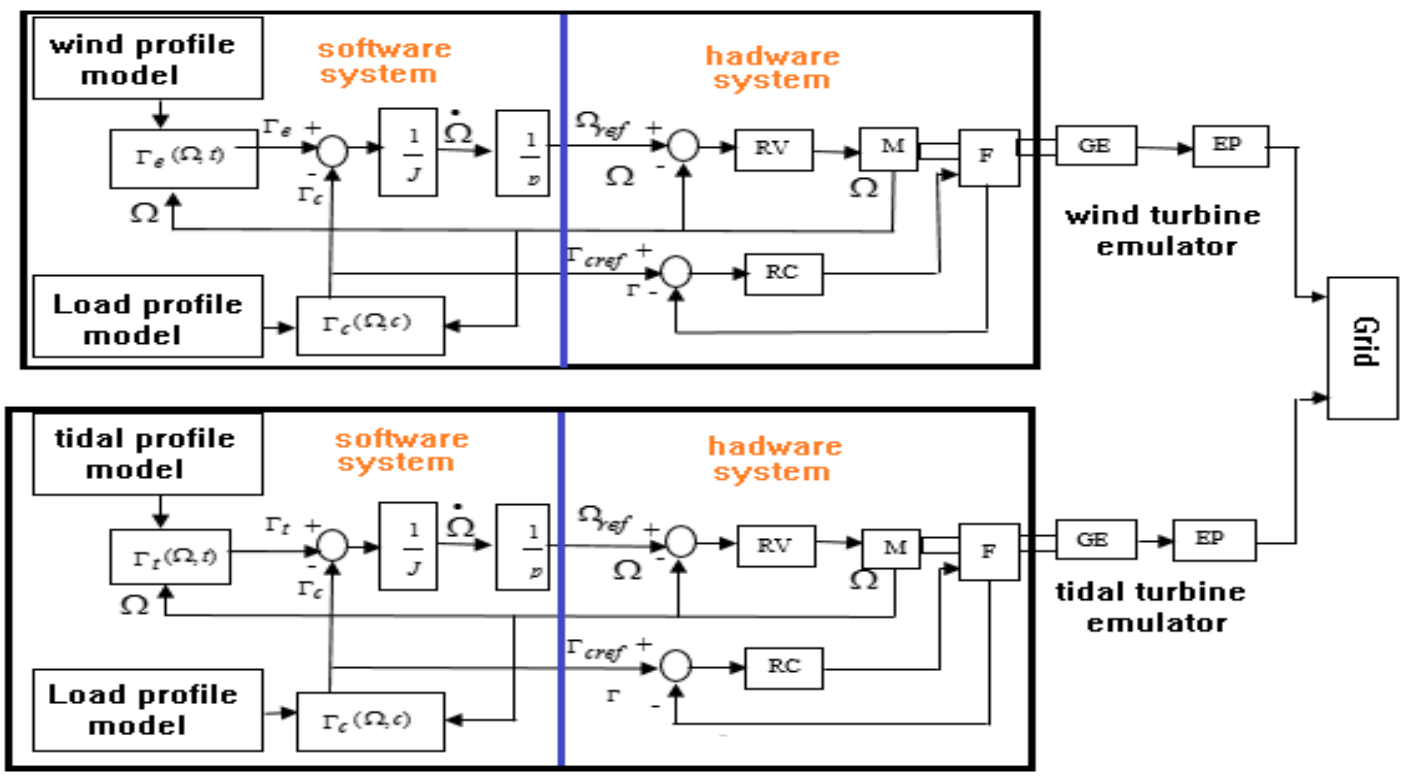

Fig.5. Structure of a hybrid wind-tidal system emulator

With:

$\Gamma_{\mathrm{e}}(\Omega, \mathrm{t}), \Gamma_{\mathrm{t}}(\Omega, \mathrm{t})$, wind and tidal turbine torque respectively; $\Gamma_{\mathrm{c}}(\Omega, \mathrm{c})$, torque of the load depending on the variations of the load ; RV and $\mathrm{RC}$, are speed and torque regulator blocks respectively; $\mathrm{M}$ and $\mathrm{F}$, are electrical motor and mechanical breaks respectively; GE and EP, are the electrical generator and static power converter respectively [12]. The emulator is composed of two subsystems:

1) A software simulator, which must be numerically realized, is describing the system to be investigated with the smallest possible errors. It generates signals that serve as references (set-points) to the hardware subsystem.

2) The multi-function hardware servo system, which receives signals generated by the software simulator, the electromechanical system consisting of two electric drives coupled mechanically.

In the emulator structure of the wind-turbine hybrid system presented above, we can notice that the emulator of the wind system is similar to that of the emulator of the tidal system, which shows and reinforces our considerations on the similarities between these two systems in their operating principles.

\section{Emulator of Wind-Tidal Hybrid System}

The experimental platform shown in figure 6 is structured based on two systems, electromechanical system and software system. the wind turbine by reproducing on its shaft the turbine static characteristics.

2) Synchronous motor emulates tidal turbine if it is needed. This electrical drive is used also as a load when single turbine is simulated. Also it is possible to generate different values of torque and as result different operating points can be obtained.

3) Doubly-Fed Induction Generator (DFIG) 2-poles is used to generate electrical power å $1.2 \mathrm{~kW}$.

4) Compacted power converter $\mathrm{AC} / \mathrm{DC}$ and $\mathrm{DC} / \mathrm{AC}$ is connected into the rotor side of the DFIG.

Software system consists of:

1) A computer unit on where the wind and tidal turbines models are implmented;

2) dSPACE unit: it is a set of hardware and software components used as communication intermediate between software and hardware systems. The hardware components consist of a DS1103 main board for fast prototyping and 2 interface boards with the PC [12] [13].

The software system is consist of programming unit, and code generation tools to simulate mathematical models [14]. The emulator also equipped with an input/output connection system for communication between computer and electromechanical system. 


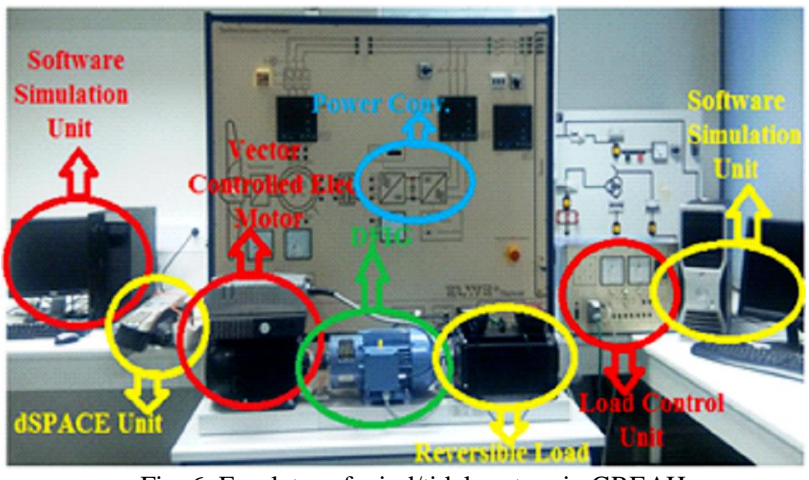

Fig. 6 Emulator of wind/tidal system in GREAH

\section{Simulation Methodology}

\section{A. Simulation in "virtual time »}

Based on the virtual time method, it is possible to extract a multi-wind profile from the original wind profile for example in this work, 300 samples of wind profile is extracted from the original wind profile 18000 samples. Hardware emulator of wind and tidal systems are used in this virtual time approach in order to reduce computational time for energy analysis of the wind and tidal power systems. Also, the operational time is reduced, experiment emulations it could be used for real time advanced control. The effect of simulation time accelerationò on the energy potential for a given site is also investigated, using Software In the Loopò (SIL) and experimentally using Hardware In the Loop (HIL) for the same given data. Figures 7 and 8 illustrate a comparison between simulation/emulator results with 18000 samples for wind profile.

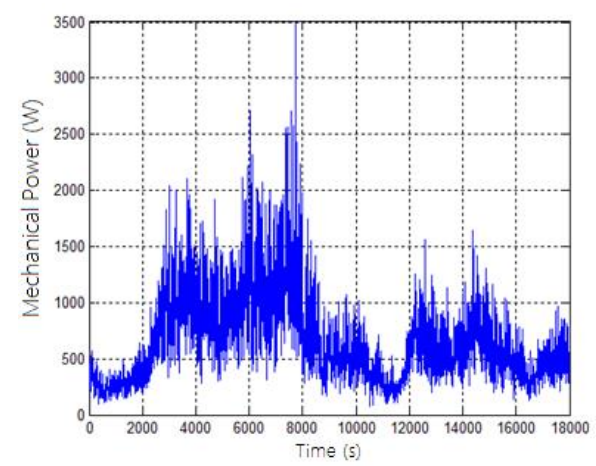

Fig.7. Generated Mechanical Power Sofware Simulation

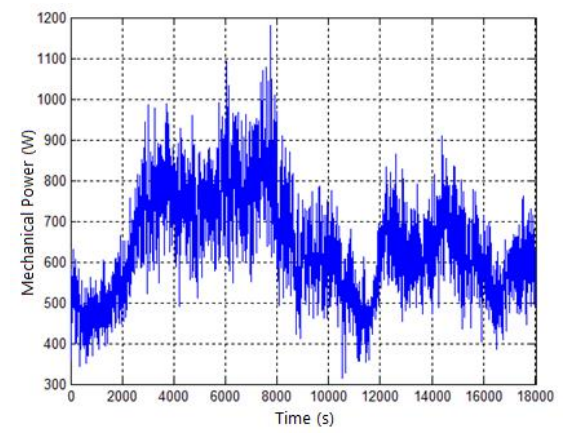

Fig.8. Generated Mechanical Power Exprimentally
The average mechanical power generated by the software simulation is $654 \mathrm{~W}$, while it is $641 \mathrm{~W}$ generated by the emulator.

This difference is generated because we use a sample every second in the software simulation, while in the emulator samples are taken every 1.2 second.

Although there is about 2\% difference between hardware emulator and software simulation but it is still acceptable results.

Figures 9 and 10 show the results obtained with time acceleration method.

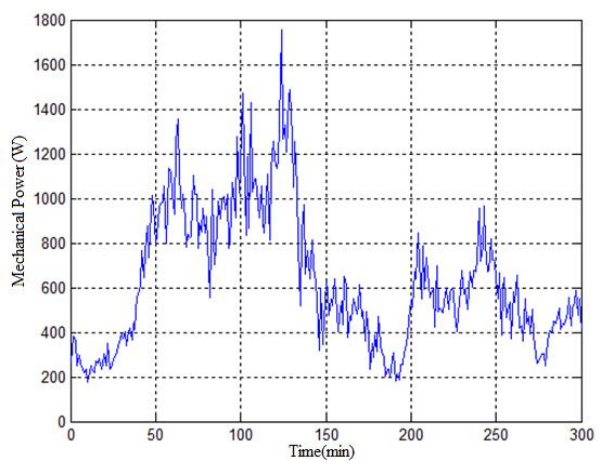

Fig. 9. Mechanical Power Generated by Software Simulation

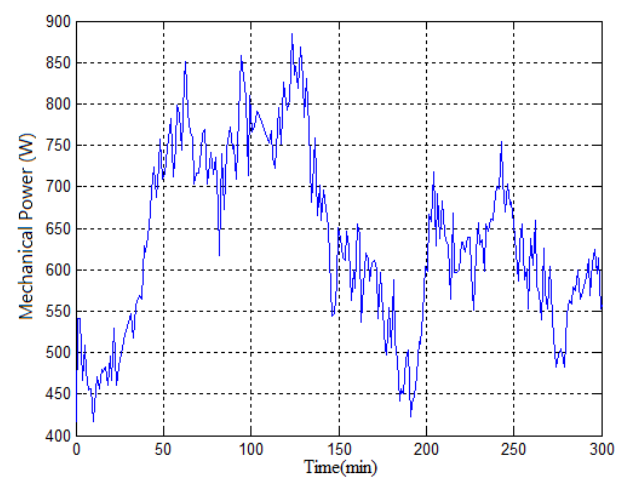

Fig. 10. Wind turbine power generated experimentally

A wind profile of 300 samples exteacted from the original wind profile, figure 9 shows the average mechanical power generated by software simulation is about $\mathrm{P} \_$average = $638 \mathrm{~W}$. Figure 10 presents the avarge mechanical power generated by emulator is about $619 \mathrm{~W}$, i.e. 1 sample/minute. So, the difference is about $3 \%$.

On the other hand, experimentally when the profile of 300 samples which generates about $641 \mathrm{~W}$, compared to the profile of 18000 samples which generates about $619 \mathrm{~W}$, the average difference is found $3.4 \%$, it is still reasonable result when comparing with time difference between the period of simulation and the number of samples.

Two major remarks emerge from these experiments:

1) Accelerated time simulation, either software or experimental, give a good approximation for variable sampling periods, in addition the system modeling is well defined; 
2) In experimental simulation, compromise is essential between the choice of sampling time and results precision.

\section{B. Simulation of electromechanical coupling wind-tidal turbines}

A new concept of a hybrid wind-tidal turbines emulator, is addressed an electro-mechanical coupling of wind turbine with hydraulic turbine on the same axis of rotation of a Doubly-Fed Induction Generator (DFIG) [13] [16].

In electromechanical coupling, it is possible to have several modes of operation:

1) Simultaneous mode operation, which makes it possible to operate two turbines at the same time (wind end tidal).

2) Single mode operation, only one turbine connected to the generator, while the other turbine is disconnected, according to certain conditions.

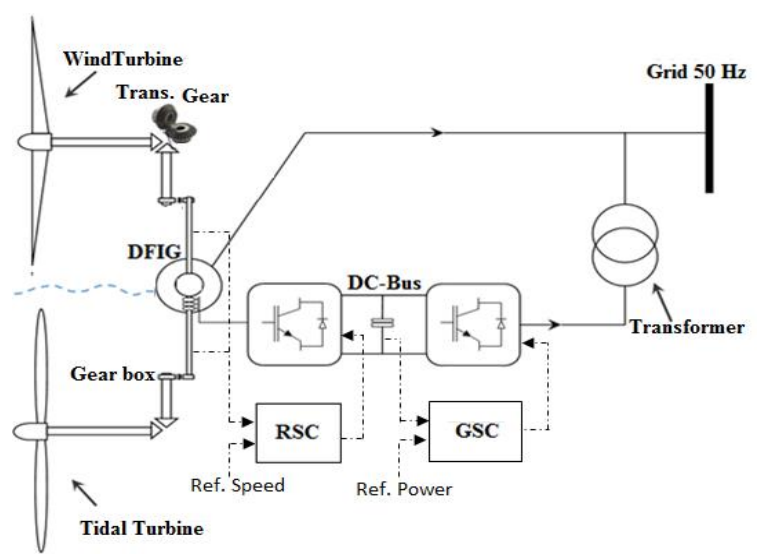

Fig. 11. Electromechanical coupling of wind/tidal turbines.

The tidal turbine can mitigate downward wind production and vice versa; the energy flow is well reinforced [17].

The wind turbine is emulated by the vector control servomotor using the HILS concept (Hardware In the Loop Simulation), and the tidal turbine is emulated by the permanent magnet synchronous machine which emulated the mechanical load in the system.

Emulation is presented further more in the following paragraph.

Based on the functional similarities between wind and tidal turbines, a small scale wind and tidal turbines are coupled on the same shaft implemented experimentally in GREAH laboratory, where a wind turbine is represented by a vector controlled asynchronous motor, while the tidal turbine is represented by synchronous permanent magnets machine, this later played the role of brake (mechanical load) in the emulator.

However, simultaneous coupling of wind and tidal turbines are simulated. For instant, supposed that the tidal speed is low and as result the turbine will be as mechanical load and will drive the electric machine under synchronous speed, then it would be inefficient for to be coupled at the same time with the wind turbine on the generatorôs shaft.

This can be the same case, by inverting whole the situation.

Figures 12 and 13 present experimental results of wind and tidal turbines coupled to the shaft of the electric generator separately [11].

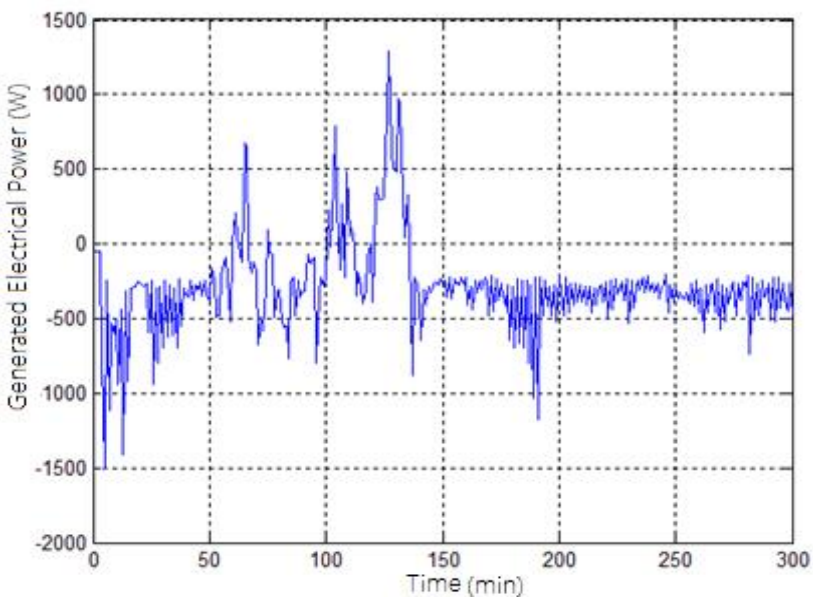

Fig. 12. Electrical Power Generated Exprimentally by Wind Turbine Only

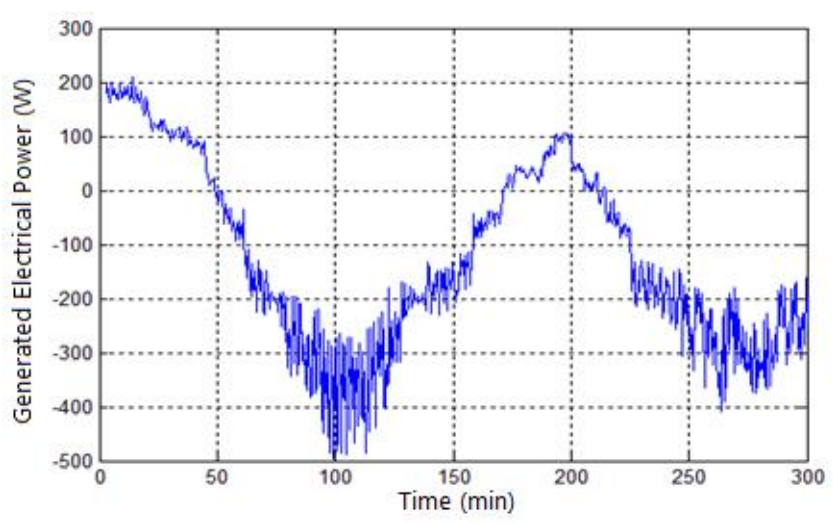

Fig. 13. electrical power generated exprimentally by tidal turbine only

Figure 14 illustrates the electrical power generated experimentally by electro-mechanical coupling wind ï tidal turbine system.

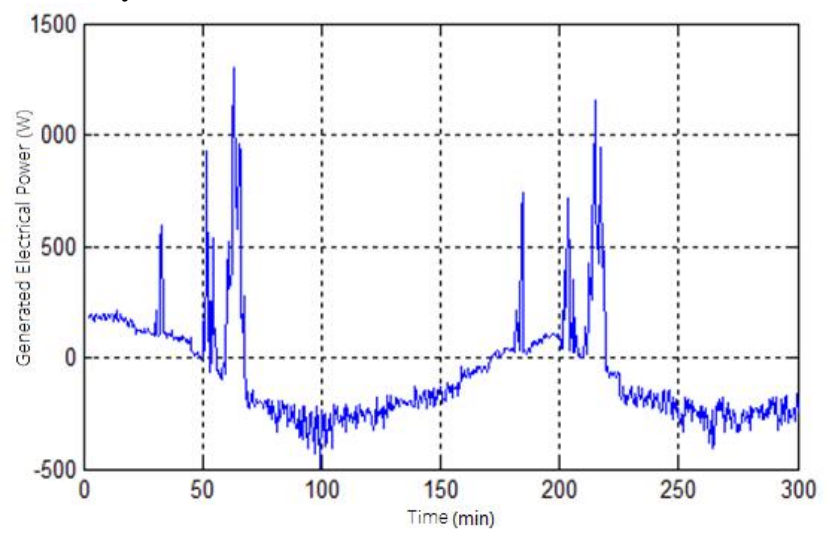

Fig. 14. Electrical power generated by hybrid system

Figure 14 shows intervals where the reference speed of rotation is lower than the speed of synchronism of i.e. 1500 revolutions / $\mathrm{min}$ the machine operates in motor mode; and 
in the intervals where the reference rotational speed is greater than the synchronism speed, the electric machine operates in generator mod.

We can also note that there are several intervals where the energy supply provided by each of the turbines, is insufficient for the operation in the generating regime of the electric machine; in this case it is necessary whether to disconnect the electric machine from the network to avoid risks operation or to add a storage and boost energy units to overcome voltage drop problems.

In this stage of the concept development, of electromechanical coupling between wind and tidal, the unit controlled electric drives are used to emulate wind and tidal turbines. These structures control were chosen during the design and the choice of the equipment and components of the emulator. In both mode of operation (hybrid system or separated systems), vector control ensures a preliminary validation and reliability of the electromechanical coupling of two renewable energy sources of different dynamics. Future development will focus on a complex control structure that must allow the fault-ride capability operations of the system and its connection to smart grids [11] [12].

\section{Conclusions}

The aim of this work is to present, on one hand, a methodology called ñaccelerated simulation timeò and its experimental validation, and on the other hand, to present the flexibility of a multi-function emulator, that allows various emulation architectures: wind turbines, tidal turbines, hybrid wind - tidal turbines systems.

It is shown by software simulation and experimental simulation that, the number of samples or time of sampling can be reduced. And as result, the simulation time is reduced with good estimation result obtained.

We obtained practically the same average values of power and rotation speed, with differences not exceeding 5\%. This allowed us to save time in simulation and calculation. This methodology could be implemented for advanced control using previsional data of wind and tidal sources.

In the second part of this work, we presented various variants of experimental turbine emulation, based on the HILS concept (Hardware In the Loop Simulation) used in the GREAH laboratory.

Furthermore, hybrid wind-tidal turbines emulator system is experimentally performed, where two turbines are coupled on the same shaft along with Doubly-Fed Induction Generator (DFIG).

The main objective is to study this concept of electromechanical and its impact on the output power of the system; the obtained results are correlated with wind and tidal speed profiles, in which statistical properties impacting global power chaine could be complementary and in particular in function of the given sites.

\section{References}

[1] G. Caraiman, ñEtude de la transposition des similitudes éolien hydrolien en vue de la conception et du développement dôn émulateur électromécanique de turbine hydrolienneò, Thèse de doctorat, Université du Havre, décembre 2011.

[2] S. Benelghali, M.E.H. Benbouzid and J. F. Charpentier, ñMarine tidal current electric power generation technology: State of the art and current status, ò in Proceedings of the 2007 IEEE IEMDC, Antalya (Turkey), vol. 2, pp. 1407-1412, May 2007.

[3] http://www.renewableenergyworld.com. ocean energy. The World's Renewable Energy. [En ligne] New Hampshire, USA, 12 July 2013. The World's 1 Renewable Energy Network for News, Information, and Companies.

[4] Jerry TEKOBON, Ferhat CHABOUR, Cristian NICHITA, " Hardware-In-the-Loop Simulation of a Hybrid Wind - Tidal Energy System ñ CISTEM 2016, Maroc, 2016.

[5] P.J. Moriarty, A.C. Hansen. AeroDyn Theory Manual Golden, Colorado : National Renewable Energy Laboratory (NREL), 2005. NREL/TP-500-36881 .

[6] Jai N. Goundar, M. Rafiuddin Ahmed. Design of a horizontal axis tidal current turbine. Applied Energy. 2013.

[7] C. Nichita, B. Dakyo, Chapitre 6. Chaines de conversion des éoliennes offshore, «Energies marines renouvelables aspects généraux, éolien, marémoteur et hydrolien ", coordinateur Bernard Multon, Editions Hermes/Lavoisier (versions en français), 2011.

[8] Wind Energy Systems Electronic Edition, by Gary L. Johnson, December 10, 2001

[9] George Caraiman , Cristian Nichita , Viorel Mînzu , Brayma Dakyo, and Chul-Hee Jo Simulation Platform for Real Time Ocean Current Energy Emulator, International Journal of Ocean System Engineering 2(1) (2012) 16-24

[10] G. Liu, S. Wang, H. Zhang, B. Wang, ñIntegrated Control Strategy of Multigrid Wind Power Generation System,ò 2012 IEEE 7th International Power Electronics and Motion Control Conference - ECCE Asia. June 2-5, 2012, Harbin, China.

[11] F. Kendouli, K. Nabti, H. Abed, K. Benalla, ñModeling, simulation and control of a turbine variable speed wind turbine based on the doubly fed induction generatorò Revue des Energies Renouvelables Vol. $14 \mathrm{~N}^{\circ} 1$ (2011) p.109 ï p. 120.

[12] C. Nichita, ñEtude et développement de structures et lois de commande numériques pour la simulation en temps réel dâactionneurs. Application à la réalisation dôn simulateur dânérogénérateur de 3 kWò, Thèse de Doctorat, Université du Havre, 1995.

[13] J. Tekobon, ñ Système multi physique de simulation pour l'étude de la production de l'énergie basée sur le couplage éolien offshore-hydrolienò, Thèse de doctorat, Normandie Université, Décembre 2016.

[14] https://www.dspace.com/shared/data/pdf/2016/dSPACE_HIL -Systems_Business-Field-Brochure_2016-03_English.pdf

[15] X. Wu, H. Figueroa, A. Monti, ñTesting of digital controllers using real-time hardware in the loop simulation,ò Power Electronics Specialists Conference, 2004. PESC 04. 2004 IEEE 35th Annual, 2004, pp. 3622-3627 Vol.5.

[16] http://techon.nikkeibp.co.jp/english/NEWS_EN/20130228/26 8591

[17] R. Isermann, J. Schaffnit, S. Sinsel, ốHardware-in-the-loop simulation for the design and testing of engine-control systemsò, Control Engineering Practice Volume 7, Issue 5, May 1999, Pages $643 і ̈ 653$. 